\title{
INTERESPECIFIC VARIATION IN THE COMPOSITION OF VOLATILE OILS FROM THE LEAVES OF Swietenia macrophylla KING (MELIACEAE)
}

\author{
Marisi Gomes Soares* \\ Departamento de Ciências Exatas, Universidade Federal de Alfenas, 37130-000 Alfenas - MG, Brasil \\ Maria Fátima das G. F. da Silva e João Batista Fernandes \\ Departamento de Química, Universidade Federal de São Carlos, 13565-905 São Paulo - SP, Brasil \\ João Henrique G. Lago \\ Departamento de Ciências Exatas e da Terra, Universidade Federal de São Paulo, 09972-270 Diadema - SP, Brasil
}

Recebido em 5/10/09; aceito em 25/1/10; publicado na web em 8/4/10

\begin{abstract}
The volatile oils from leaves of five Brazilian specimens of Swietenia macrophylla King (Meliaceae) collected in three different Amazon Rainforest Conservation Areas in the States of Mato Grosso, Pará, and Rondônia were extracted and analyzed by GC and GC/MS. The oils showed to be composed by terpenoids, majority hydrocarbon sesquiterpenes, being germacrene $\mathrm{D}(20.5-46.8 \%)$ and bicyclogermacrene (8.3-11.1\%) the main components. Besides these derivatives, only $\alpha$-cubebene, $\beta$-caryophyllene, $\beta$-gurjunene and $\gamma$-cadinene were detected in all of the analyzed samples. This analysis indicated a great diversity of constituents in the oils obtained from specimens collected in these regions, which could be associated to the different susceptibility in the attack of $H$. grandella in S. macrophylla cultures.
\end{abstract}

Keywords: Swietenia macrophylla King; Meliaceae; volatile oil composition.

\section{INTRODUCTION}

Swietenia macrophylla King (mahogany) is a valuable and intensively exploited neo-tropical timber species whose seedling survival and growth dynamics in natural forests are poorly understood. ${ }^{1}$ Chemically, this species is characterized by expressive production of limonoids, which are highly oxygenated degraded triterpenes, characteristics from Meliaceae. ${ }^{2-4}$

Previous investigation of the volatile oils from shoots, mature and senescent leaves from S. macrophylla, collected in Igarapé-Açú/ $\mathrm{PA}$, indicated the presence of several compounds including germacrene $\mathrm{D}$, hexadecanoic acid, and its respective ethyl ester derivative. Additionally, electroantennograms of both female and male borer moths revealed significant responses to the volatile oil obtained from terminal shoots, mature and senescent leaves from S. macrophylla. The GC-EAD of the volatile oil from the mature leaves of $S$. macrophylla suggests $\beta$-caryophyllene as the main constituent responsible for antennal response in female $H$. grandella antennae. ${ }^{5}$

Several works describe that the same species grown in different areas could exhibit variations in the composition of its volatile oils, ${ }^{6,7}$ but no information about dynamic of volatile derivatives from $S$. macrophylla has previously been described in the literature. Therefore, the purpose of this work was to assess the volatile oil variation from the leaves of different specimens of $S$. macrophylla collected in five different regions of Amazon Rainforest Conservation Areas (Juína/MT, Morada do Sol/PA, Santarém/PA, Vila Progresso/PA, and Ariquemes/RO).

\section{EXPERIMENTAL}

\section{Plant material}

The leaves of Swietenia macrophylla King (Meliaceae) were randomly collected on $14^{\text {th }}$ November 1999 (at 9-11 a.m.) from three Amazon Rainforest Conservation Areas in the States of Mato Grosso

*e-mail: marisigs@gmail.com
(Juína - 1), Pará (Morada do Sol - 2, Santarém - 3, Vila Progresso - 4), and Rondônia (Ariquemes - 5). The plant materials were compared with those previously analyzed $\mathrm{d}^{4,5}$ and voucher specimens were deposited in the Herbarium of the Museum Paraense Emílio Goeldi, Belém, Pará, Brazil.

\section{Volatile oil extraction}

Immediately after collection, the fresh leaves (400 g) were steamdistilled in a Clevenger-type apparatus for $4 \mathrm{~h}$. After extraction, the crude oils were dried over anhydrous $\mathrm{Na}_{2} \mathrm{SO}_{4}$, filtered and stored at -20 ${ }^{\circ} \mathrm{C}$ in the dark until analyzed. The yield of each extraction was calculated based on the weight of fresh leaves. Quantitative and qualitative analysis of the oils were performed by GC and GC/MS, respectively.

\section{Qualitative and quantitative analysis}

CG analysis were performed in a Hewlett-Packard 5890 Series II gas chromatograph (using helium as carrier gas) equipped with an FID detector, and automatic injector (HP 7673) and electronic integrator (HP3396A). The GC was fitted with a capillary column (HP-5, $30 \mathrm{~m}$ $0.32 \mathrm{~mm}$, I.D., $0.25 \mu \mathrm{m}$ film thickness) with a stationary phase of $5 \%$ cross-linked phenyl in $95 \%$ silicone, temperature programming was performed as follows: constant $100{ }^{\circ} \mathrm{C}$ for $2 \mathrm{~min}$, a linear ramp from $100-240{ }^{\circ} \mathrm{C}$ at $5{ }^{\circ} \mathrm{C} \mathrm{min}^{-1}$, then held at constant $240{ }^{\circ} \mathrm{C}$ for 5 min. Injector (FID) and detector temperatures were 180 and $260{ }^{\circ} \mathrm{C}$, respectively. Relative component concentrations were calculated from GC peak areas in the order of DB-5 column elution. ${ }^{8}$

CG/MS analysis was carried out in an Hewlett-Packard HP-5973 EIMS $(70 \mathrm{eV})$ coupled with a Hewlett-Packard HP-6890 with HP-5 column ( $30 \mathrm{~m} 0.25 \mathrm{~mm}$, I.D., $0.25 \mu \mathrm{m}$ film thickness) using the same temperature-programming conditions described above. The identification of the components was based on the comparison of their EI mass spectra with those in the system's spectral library (Willey 229) and confirmed by calculation of their Kovats retention indexes (RI), which were determined relatively to the retention times of a series on $n$-alkanes $\left(\mathrm{C}_{8}\right.$ to $\left.\mathrm{C}_{20}\right)$ as described in the literature. ${ }^{9,10}$ 
Table 1. Data of each collection from leaves of Swietenia macrophylla, yield, content (in percentage) and composition of respective volatile oils

\begin{tabular}{|c|c|c|c|c|c|c|}
\hline & & 1 & 2 & 3 & 4 & 5 \\
\hline Collection site & & Juína / MT & Morada do Sol / PA & Santarém / PA & Vila Progresso / PA & Ariquemes / RO \\
\hline Volatile oil yield $(\%)$ & & 0.14 & 0.12 & 0.13 & 0.17 & 0.21 \\
\hline Compounds & $\mathrm{KI}$ & & & & & \\
\hline Tricyclene & 926 & - & - & - & 0.19 & - \\
\hline Benzaldehyde & 961 & - & - & - & 1.10 & - \\
\hline Sabinene & 976 & - & - & 0.24 & 0.16 & 0.53 \\
\hline NI (MM 136) & 964 & 0.58 & - & 0.05 & - & - \\
\hline NI (MM 138) & 989 & - & - & 0.35 & 3.51 & - \\
\hline Isosylvestrene & 1007 & - & - & - & 0.97 & - \\
\hline$\Delta^{3}$-Carene & 1011 & - & 0.48 & - & - & - \\
\hline Limonene & 1031 & - & - & 0.43 & 2.99 & 2.21 \\
\hline$(Z)-\beta$-Ocimene & 1040 & - & - & 0.11 & 0.27 & 0.22 \\
\hline Benzene acetaldehyde & 1043 & - & - & - & 0.10 & - \\
\hline$(E)$ - $\beta$-Ocimene & 1050 & - & - & 0.31 & 1.20 & - \\
\hline$\gamma$-Terpinene & 1062 & - & - & - & - & 0.24 \\
\hline Acetophenone & 1065 & - & - & - & 0.89 & - \\
\hline NI (MM 136) & 1080 & - & 0.51 & 0.01 & - & - \\
\hline Pinocampheol & 1170 & - & - & - & 0.90 & 0.48 \\
\hline Terpin-4-ol & 1177 & - & - & - & 0.63 & 0.47 \\
\hline NI (MM 152) & 1215 & - & 0.97 & 0.04 & - & - \\
\hline NI (MM 152) & 1219 & - & - & - & 0.36 & 0.42 \\
\hline NI (MM 152) & 1222 & - & - & 0.04 & - & 0.34 \\
\hline$(E, Z)$-2,4-Decadienal & 1291 & - & - & 0.29 & - & - \\
\hline$(E, E)$-2,4-Decadienal & 1314 & 0.34 & 0.48 & - & 0.95 & 0.29 \\
\hline$\delta$-Elemene & 1339 & 0.19 & - & - & - & - \\
\hline$\alpha$-Cubebene & 1351 & 0.44 & 0.60 & 0.98 & 0.92 & 0.96 \\
\hline Eugenol & 1356 & - & - & - & - & 0.21 \\
\hline Cyclosativene & 1368 & - & - & 1.23 & - & - \\
\hline$\alpha$-Ylangene & 1372 & 4.73 & - & - & 2.90 & 1.69 \\
\hline$\alpha$-Copaene & 1376 & - & 5.09 & 3.16 & - & - \\
\hline$\beta$-Bourbonene & 1384 & 0.51 & 1.23 & - & 1.45 & 1.23 \\
\hline$\beta$-Cubebene & 1390 & - & 1.88 & 4.91 & 3.10 & 1.62 \\
\hline$\beta$-Elemene & 1390 & 1.52 & - & - & - & - \\
\hline$\alpha$-Gurjunene & 1409 & - & - & 2.40 & 1.32 & - \\
\hline$\beta$-Caryophyllene & 1418 & 1.40 & 0.27 & 2.23 & 0.15 & 1.83 \\
\hline NI (MM 202) & 1420 & 0.29 & 2.79 & - & 0.88 & 1.04 \\
\hline$\beta$-Gurjunene & 1432 & 0.74 & 2.29 & 2.15 & 2.55 & 1.67 \\
\hline NI (MM 204) & 1434 & 2.54 & - & - & - & 2.22 \\
\hline NI (MM 204) & 1449 & 1.07 & - & - & - & 1.34 \\
\hline$\alpha$-Humulene & 1454 & - & 0.58 & - & - & 0.33 \\
\hline Cis-Muurola-4(14),5-diene & 1460 & - & - & 1.32 & - & - \\
\hline Allo-Aromadendrene & 1461 & 1.79 & - & - & - & 0.92 \\
\hline NI (MM 202) & 1462 & 1.33 & - & 0.92 & - & 1.88 \\
\hline (E)-9-epi-Caryophyllene & 1467 & - & - & 3.39 & - & - \\
\hline$\gamma$-Gurjunene & 1477 & - & - & - & 1.58 & - \\
\hline Germacrene-D & 1480 & 46.83 & 20.47 & 23.06 & 45.66 & 43.61 \\
\hline$\beta$-Ionone & 1485 & - & - & - & 1.65 & - \\
\hline Valence & 1491 & - & - & - & 1.46 & - \\
\hline Bicyclogermacrene & 1494 & 8.26 & 9.23 & 11.11 & 8.54 & 8.34 \\
\hline$\alpha$-Muurolene & 1499 & - & - & - & 0.65 & 1.46 \\
\hline Germacrene-A & 1503 & 1.29 & 3.75 & 3.57 & 2.80 & - \\
\hline$\gamma$-Cadinene & 1513 & 3.32 & 4.15 & 3.98 & 0.62 & 1.57 \\
\hline Cis-Calamenene & 1521 & - & 1.74 & - & - & - \\
\hline$\delta$-Cadinene & 1524 & 4.70 & - & 5.22 & 1.24 & 2.52 \\
\hline Cadina-1,4-diene & 1532 & - & - & 0.83 & - & 0.81 \\
\hline
\end{tabular}


Table 1. Continuation

\begin{tabular}{|c|c|c|c|c|c|c|}
\hline & & 1 & 2 & 3 & 4 & 5 \\
\hline Collection site & & Juína / MT & Morada do Sol / PA & Santarém / PA & Vila Progresso / PA & Ariquemes / RO \\
\hline Volatile oil yield (\%) & & 0.14 & 0.12 & 0.13 & 0.17 & 0.21 \\
\hline Compounds & $\mathrm{KI}$ & & & & & \\
\hline Trans-Calamenene & 1532 & - & 1.30 & - & - & - \\
\hline$\alpha$-Cadinene & 1538 & 0.12 & - & 3.94 & 1.35 & 1.27 \\
\hline NI (MM 204) & 1568 & - & 0.85 & 0.34 & - & 0.32 \\
\hline Spathulenol & 1576 & - & 4.07 & - & - & 1.49 \\
\hline NI (MM 222) & 1581 & - & 0.56 & - & - & 0.61 \\
\hline NI (MM 222) & 1589 & 1.18 & - & 0.71 & - & 0.82 \\
\hline Humulene Epoxide II & 1606 & - & 1.38 & - & - & - \\
\hline NI (MM 222) & 1615 & 2.12 & - & - & - & 2.95 \\
\hline 1-epi-Cubenol & 1627 & 1.01 & 1.88 & 1.39 & - & - \\
\hline Epi- $\alpha$-Cadinol & 1641 & 2.04 & 7.79 & 4.93 & - & - \\
\hline NI (MM 222) & 1654 & - & 6.98 & 2.39 & - & 1.43 \\
\hline Cis-14-Murolol-5-en-4-one & 1682 & - & 3.96 & - & - & - \\
\hline NI (MM 220) & 1686 & 0.36 & - & 0.11 & - & 0.22 \\
\hline NI (MM 220) & 1763 & - & - & 0.09 & - & 0.35 \\
\hline Methyl hexadecanoate & 1927 & 1.74 & 5.33 & 2.52 & - & 0.59 \\
\hline Ethyl Hexadecanoate & 1993 & - & - & 1.23 & 0.43 & 0.72 \\
\hline NI (MM 272) & 2035 & 0.10 & - & 0.04 & - & 0.09 \\
\hline Methyl linoleate & 2092 & 0.50 & - & - & - & 0.68 \\
\hline Methyl octadecanoate & 2129 & 0.11 & - & - & 0.85 & - \\
\hline E-Phytol Acetate & 2221 & - & - & - & - & 0.41 \\
\hline Monoterpene hydrocarbons & & - & 0.48 & 1.09 & 5.78 & 3.20 \\
\hline Oxygenated monoterpenes & & - & - & - & 1.56 & 0.95 \\
\hline Sesquiterpene hydrocarbons & & 75.84 & 52.58 & 73.48 & 75.37 & 69.83 \\
\hline Oxygenated sesquiterpenos & & 3.05 & 19.08 & 6.32 & 1.65 & 1.49 \\
\hline Other compounds & & 2.69 & 5.81 & 4.04 & 3.27 & 2.90 \\
\hline Total identified & & 81.58 & 77.95 & 84.93 & 89.57 & 78.37 \\
\hline Total not identified & & 9.57 & 12.66 & 5.09 & 4.75 & 12.69 \\
\hline TOTAL & & 91.15 & 90.61 & 90.02 & 94.32 & 91.06 \\
\hline
\end{tabular}

\section{RESULTS AND DISCUSSION}

Data of each collection of leaves of S. macrophylla as well as the volatile oils yields are shown in Table 1 . These data indicate that the specimens from Ariquemes (5) and Vila Progresso (4) regions present the greatest oils content $(0.21$ and $0.17 \% \mathrm{w} / \mathrm{w}$, respectively) followed by the oils from Juína (1), Morada do Sol (2), and Santarém (3), which showed similar yields $(0.12-0.14 \%$ w/w). Comparatively, the yields of these five analyzed specimens were higher of those detected previously to $S$. macrophylla from Igarapé-Açú, which were calculated as $0.048 \%$ to mature and $0.047 \%$ to senescent leaves. ${ }^{5}$

Chemically, the crude oils were analyzed by CG and CG/MS which lead to the identification of fifty-four constituents for which together account for $77.9-89.6 \%$ of the total oil content. The relative amounts of each component in the crude oils are presented in Table 1. In the five analyzed oil samples, the predominant components were hydrocarbon sesquiterpene derivatives, including $\alpha$-cubebene, $\beta$-caryophyllene, $\beta$-gurjunene, germacrene $\mathrm{D}$, bicyclogermacrene and $\gamma$-cadinene, all of which were detected in the five studied specimens. These data also showed the predominance of germacrene-D in the five analyzed oils, with its relative abundance being higher in specimens 1 (46.83\%), 4 (45.66\%) and $\mathbf{5}(43.61 \%)$, similar to the oils previously analyzed. ${ }^{5}$ A biogenetically related compound from germacrene $\mathrm{D},{ }^{11}$ the sesquiterpene bicyclogermacrene, was detected as the second most abundant derivative with a similar composition in specimens $\mathbf{1}(8.26 \%), \mathbf{2}(9.23 \%), \mathbf{4}(8.54 \%)$, and $\mathbf{5}(8.34 \%)$, but with a higher relative amount in specimen $3(11.11 \%)$.

The combined relative amounts of hydrocarbon sesquiterpenes were shown to be similar (69.83-75.84\%) in the oils from leaves collected in regions $\mathbf{1 , 3 , 4}$, and $\mathbf{5}$. Comparatively, the oil from region 2 showed a lower relative amount of non-oxygenated $\mathrm{C}_{15}$ derivatives $(52.58 \%)$. In contrast, the relative proportion of oxygenated derivatives in the oil from region 2 was approximately $20 \%$, with epi- $\alpha$-cadinol being the major compound (7.79\%). Despite of the monoterpenes have been detected as minor derivatives in the crude oils, a higher proportion of these compounds was observed in specimens 4 (7.34\%) and $\mathbf{5}(4.15 \%)$, in which limonene was the major component in both oils (2.99\% and $2.21 \%$, respectively). Otherwise, the occurrences of these $\mathrm{C}_{10}$ derivatives was not observed in the oil from specimen $\mathbf{1}$, but were detected only in very low amounts in the oils from specimens $\mathbf{2}$ and $\mathbf{3}$, similar to what had been observed in other Meliaceae specimens. ${ }^{12-14}$

Finally, observations in the field showed that trees from distinct geographic origin exhibited a differentiation in their susceptibility to attack by $H$. grandella.$^{15}$ As determined previously by GC/EAD measurements, ${ }^{5}$ the sesquiterpene $\beta$-caryophyllene could play a role in attracting $H$. grandella to lay its eggs on the leaves of S. macrophylla. In the present work, the distinctive abundance of $\beta$-caryophyllene in each one of the five analyzed oils could partially explain the different behavior of the attack of this lepdopterous in S. macrophylla 
cultures. ${ }^{15}$ In summary, the results presented here provide additional information concerning the chemical variation in volatile oils from $S$. macrophylla, indicating that the ecological relationship of these volatile oils and $H$. grandella require further detailed investigation.

\section{ACKNOWLEDGMENTS}

Authors thank to Fundação de Amparo à Pesquisa do Estado de São Paulo (FAPESP) and Conselho Nacional de Desenvolvimento Cientifico e Tecnológico $(\mathrm{CNPq})$ for their financial support of this work. We also thank Dr. L. Bonilla (i-Ventures LTDA) for editing the final version of this manuscript.

\section{SUPPLEMENTARY MATERIAL}

Available in http://quimicanova.sbq.org.br, in format PDF, with free access.

\section{REFERENCES}

1. Grogan, J.; Landis, R. M.; Ashton, M. S.; Galvao, J.; For. Ecol. Manag. 2005, 204, 399.

2. Taylor, A. R. H.; Taylor, D. A. H.; Phytochemistry 1983, 22, 2870.

3. Dewanjee, S.; Maiti, A.; Das, A. K.; Mandal, S. C.; Dey, S. P.; Fitoterapia 2009, 80, 249.
4. Schefer, A. B.; Braumann, U.; Tseng, L. -H.; Spraul, M.; Soares, M. G.; Fernandes, J. B.; Silva, M. F. G. F.; Vieira, P. C.; Ferreira, A. G.; J. Chromatogr. 2006, 1128, 152.

5. Soares, M. G.; Batista-Pereira, L. G.; Fernandes, J. B.; Correa, A. G.; Silva, M. F. G. F.; Vieira, P. C.; Rodrigues-Filho, E.; Ohashi, O. S.; J. Chem. Ecol. 2003, 29, 2143.

6. Lago, J. H. G.; Brochini, C. B.; Roque, N. F.; J. Essent. Oil Res. 2005, $17,271$.

7. Gobbo-Neto, L.; Lopes, N. P.; Quim. Nova 2007, 30, 374.

8. Adams, R. P.; Identification of Volatile Oil Components by Gas Chromatography / Mass Spectroscopy, $4^{\text {th }}$ ed., Allured Publishing Corporation: Carol Stream, 2007.

9. van den Dool, H.; Kratz, D. J.; J. Cromatogr. 1963, 11, 463.

10. Lago, J. H. G.; Romoff, P.; Fávero, O. A.; Soares, M. G.; Baraldi, P. T.; Corrêa, A. G.; Souza, F. O.; Quim. Nova 2008, 31, 727.

11. Bülow, N.; König, W. A.; Phytochemistry 2000, 55, 141.

12. Brochini, C. B.; Lago, J. H. G.; Roque, N. F.; Nat. Prod. Res. 2009, 23, 1615 .

13. Lago, J. H. G.; Reis, A. A.; Roque, N. F.; Flav. Frag. J. 2002, 17, 255.

14. Lago, J. H. G.; Soares, M. G.; Batista-Pereira, L. G.; Silva, M. F. G. F.; Correa, A. G.; Fernandes, J. B.; Vieira, P. C.; Roque, N. F.; Phytochemistry 2006, 67, 589.

15. Pérez-Salicrup, D.; Esquivel, R.; For. Ecol. Manage. 2008, 255, 324. 


\section{INTERESPECIFIC VARIATION IN THE COMPOSITION OF VOLATILE OILS FROM THE LEAVES OF Swietenia} macrophylla KING (MELIACEAE)

Marisi Gomes Soares*

Departamento de Ciências Exatas, Universidade Federal de Alfenas, 37130-000 Alfenas - MG, Brasil

Maria Fátima das G. F. da Silva e João Batista Fernandes

Departamento de Química, Universidade Federal de São Carlos, 13565-905 São Paulo - SP, Brasil

João Henrique G. Lago

Departamento de Ciências Exatas e da Terra, Universidade Federal de São Paulo, 09972-270 Diadema - SP, Brasil

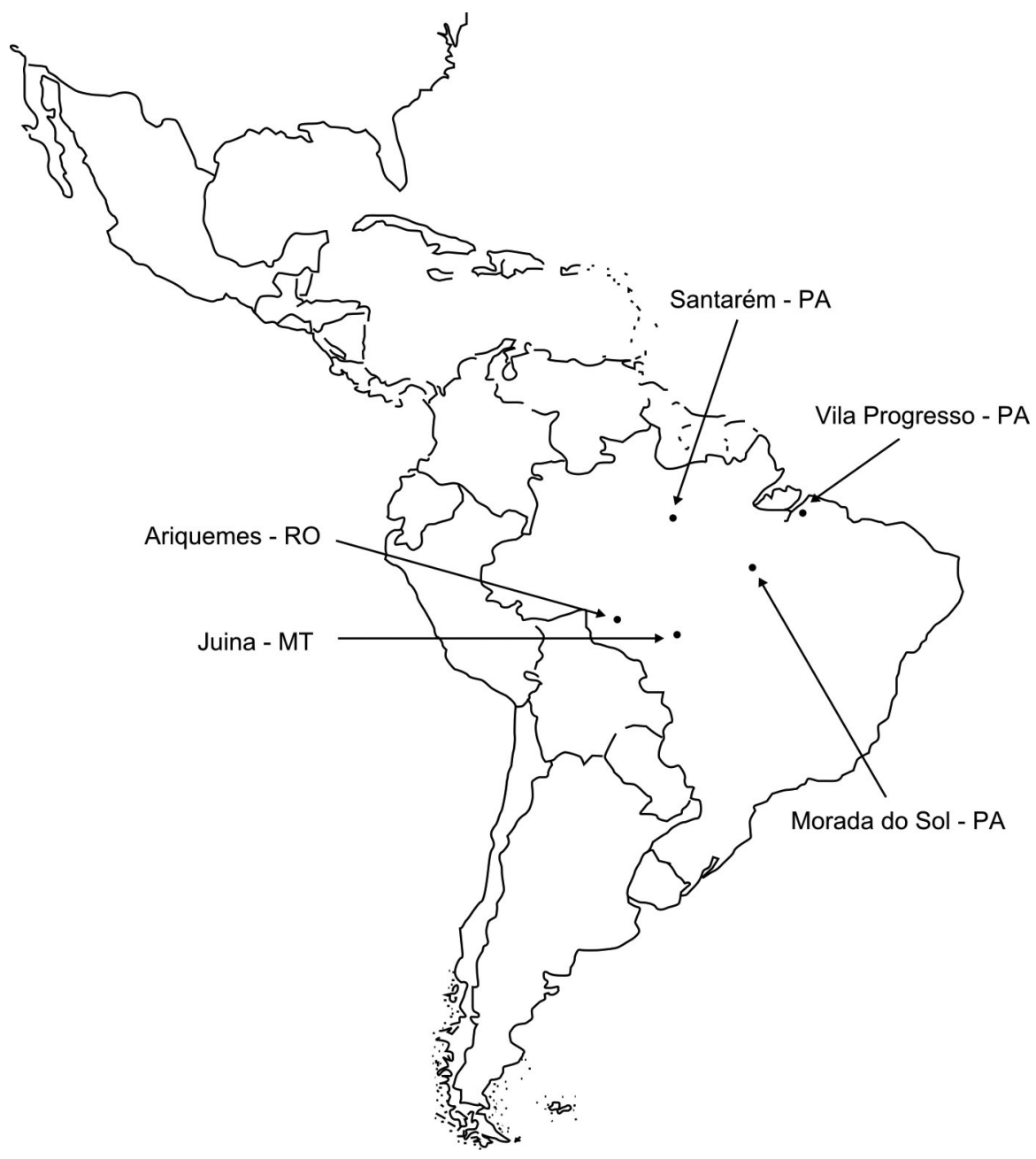

Figure 1S. Brazilian Amazon Forest conservation areas in which the five specimens of S. macrophylla were collected - Juina/MT (1), Morada do Sol/PA (2), Santarém/PA (3), Vila Progresso/PA (4), and Ariquemes/RO (5) 